\title{
Arsenic species in husked and polished rice grains grown at the non- contaminated paddy soils in Korea
}

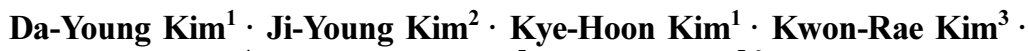 \\ Hyuck-Soo Kim ${ }^{4}$ Jeong-Gyu Kim ${ }^{5}$. Won-Il Kim ${ }^{5,6}$ (D)
}

\section{국내 비오염 논토양에서 재배한 현미와 백미 중 비소화학종 함량}

\author{
김다영 ${ }^{1} \cdot$ 김지영 ${ }^{2}$ - 김계훈 ${ }^{1} \cdot$ 김권래 $^{3} \cdot$ 김혁수 $^{4} \cdot{\text { 김정 } 7^{5} \text { - 김원일 }}^{5,6}$
}

Received: 1 October 2018 / Accepted: 13 November 2018 / Published Online: 31 December 2018

(C) The Korean Society for Applied Biological Chemistry 2018

\begin{abstract}
There is an increasing concern over arsenic (As) contamination of paddy soil and rice with regard to food safety. This study was conducted to investigate total and inorganic As concentration in one hundred husked and polished rice samples collected at the non-contaminated paddy soil in Korea. Arsenic species in rice samples were extracted using $1 \%$ nitric acid $\left(\mathrm{HNO}_{3}\right)$ with a microwave oven and were measured using high performance liquid chromatography coupled with inductively
\end{abstract}

Da-Young Kim and Ji-Young Kim are equally contributed.

Won-Il Kim $(\bowtie)$

E-mail:wikim0721@naver.com

${ }^{1}$ Department of Environmental Horticulture, University of Seoul, Seoul 02504, Republic of Korea

${ }^{2}$ Imported Food Analysis Division, Seoul Regional Food Drug Administration, Seoul 07978, Republic of Korea

${ }^{3}$ Department of Agronomy and Medicinal Plant Resources, Gyeongnam National University of Science and Technology, Jinju 52725, Republic of Korea

${ }^{4}$ Department of Biological Environment, Gangwon National University, Chuncheon 24341, Republic of Korea

${ }^{5}$ O-Jeong Eco-Resilience Institute, Korea University, Seoul 02841, Republic of Korea

${ }^{6}$ Chemical Safety Division, National Institute of Agricultural Science, Wanju 55365, Republic of Korea

This is an Open Access article distributed under the terms of the Creative Commons Attribution Non-Commercial License (http://creativecommons. org/licenses/by-nc/3.0/) which permits unrestricted non-commercial use, distribution, and reproduction in any medium, provided the original work is properly cited. coupled plasma-mass spectrometry. Mean concentrations of total As in husked rice and polished rice were 0.18 and $0.11 \mathrm{mg} \mathrm{kg}^{-1}$, respectively. Also, average inorganic As concentrations in husked rice and polished rice were 0.11 and $0.07 \mathrm{mg} \mathrm{kg}^{-1}$, respectively. These levels are lower than the standard guideline value 0.35 and $0.2 \mathrm{mg} \mathrm{kg}^{-1}$ for inorganic As in husked and polished rice recommended by Codex Committee on Contaminants in Foods and Ministry of Food and Drug Safety, respectively. The mean of the inorganic As ratio for the total amount of As was 0.65 and 0.67 for husked rice and polished rice, respectively, and the range was from 0.08 to 1.0. For health risk assessment, the average value of cancer risk probability was $9.24 \times 10^{-5}$ and ranged from $2.30 \times 10^{-5}$ to $1.90 \times 10^{-4}$. Therefore, human exposure to As through dietary intake of surveyed rice samples might considered to be a low health risk.

Keywords Arsenic $\cdot$ Husked rice $\cdot$ Inorganic arsenic $\cdot$ Monitoring Polished rice

\section{서 론}

쌀은 전세계 인구의 $50 \%$ 가량이 주식으로 이용하고 있다. 또 한, 방글라데시, 인도, 베트남 등 많은 아시아 국가에 있어서 쌀 의 비소오염은 농업에서 가장 심각한 문제 중 하나로 인식되고 있다. 특히 관개용수를 많이 필요로 하는 벼농사의 경우, 비소 로 오염된 관개용수를 사용한 쌀 중 비소함량이 높다는 보고가 지속되고 있다[1-3]. 최근, 세계식량기구(Food and Agricultural Organization, FAO)와 세계보건기구(World Health Organization, 
$\mathrm{WHO}$ )가 공동 주관하는 식품기준 규격위원회 오염물질분과위원 회(Codex Committee on Contaminants in Foods; CCCF)는 백미와 현미의 무기비소 기준을 각각 0.2 과, $0.35 \mathrm{mg} \mathrm{kg}^{-1}$ 으로 설정하고 회원국에 권장기준으로 제시하였다[4,5]. 그동안, 쌀 중 무기비소 기준설정에 관한 논의에서는 쌀 중 무기비소 함량에 관한 중국, 일본, 미국, $\mathrm{EU}$ 등 10 여개국 자료를 검토하였으나 국내의 자료는 활용되지 않았다. 쌀 중 비소에 관한 국내 모니 터링 결과는 주로 백미와 현미의 총비소 함량으로 보고[6-8]되 었고, 무기비소의 보고는 최근에 활발이 진행되고 있다. Paik 등 [9]은 $1 \%$ 질산을 함유한 methanol-water $(1: 1)$ 혼합액으로 추출 하여 high performance liquid chromatography coupled with inductively coupled plasma-mass spectrometry (HPLC-ICP$\mathrm{MS}$ )로 분석한 백미 중 무기비소 함량이 $8.6-37.2 \mu \mathrm{g} \mathrm{kg}^{-1}$ 으로 총 비소의 35.4-73.3\%를 차지하는 것으로 보고하였다. Kim 등[10] 은 $1 \%$ 질산으로 추출한 30 점의 백미 시료에서 무기비소 함량 이 평균 $0.085 \mathrm{mg} \mathrm{kg}^{-1}$ 와 총비소에 대한 무기비소의 비율이 $54.5-87.86 \%$ 로 보고하였다. 또한 $\mathrm{Kim}$ 등[11]은 폐광산 인근에 서 채취한 현미와 백미 중 무기비소 함량이 각각 $0.09 \mathrm{mg} \mathrm{kg}^{-1}$ $\left(0.02-0.31 \mathrm{mg} \mathrm{kg}^{-1}\right), 0.05 \mathrm{mg} \mathrm{kg}^{-1}\left(0.01-0.11 \mathrm{mg} \mathrm{kg}^{-1}\right)$ 으로 조사 되었고 이에 대한 위해성 평가로 인체에 미치는 위해성이 미미 한 것으로 보고하였다. 그러나, 전국적인 단위의 쌀 중 무기비 소 함량에 관한 보고는 극히 제한적이다. 따라서 본 연구는 우 리나라 중금속 비오염 쌀 주산단지 논토양에서 생산된 현미와 백미 중 비소 화학종 함량에 대한 현황을 파악하고 쌀 중 비소 기준설정 및 쌀의 비소오염에 대한 안전관리의 기초 자료를 제 공하고자 한다.

\section{재료 및 방법}

\section{대상지역과 쌀시료 채취 및 조제}

본 연구에서는 논토양에서 중(준)금속의 오염이 예상되는 광산 인근 및 공단인근 지역을 배제한 우리나라 지역별 쌀 주산단지 로 경기, 강원, 충남, 충북, 전북, 전남, 경북, 경남도별로 각각 12-13지점에서 2013년 재배한 총 100점을 채취하여 시료로 사 용하였다. 수확한 쌀 시료를 풍건한 후, 드라이오븐에서 $60{ }^{\circ} \mathrm{C}$ 로 하루 건조 후 현미기(SYTH88, Ssangyong Instrument, Incheon, Korea)를 이용하여 현미로 도정하였고, 실험용 도정기 (McGill miller, HT McGill Inc, Brookshire, TX, USA)를 이용하여 10 분도 백미로 도정하였다. 도정된 현미와 백미는 1 분 동안 자동 균질기를 사용하여 고운 가루로 빻아서 실온에 보관하였고 분 석시료로 사용하였다.

\section{쌀 중 비소함량 분석}

현미와 백미의 총 비소 함량 분석은 분쇄한 시료 $0.25 \mathrm{~g}$ 을 마 이크로웨이브(Mars5, CEM, Matthews, NC, USA) 분해용기에 넣고 진한 질산 $8 \mathrm{~mL}$ 와 $30 \%$ 과산화수소 $1 \mathrm{~mL}$ 를 첨가한 후 1 시간 정치시켜 발생하는 가스를 제거하고, 모든 vessel은 screw cap으로 밀봉하여 설정된 프로그램에 의해 microwave digestion system (ETHOS, Milestone, Sorisole, Vergamo, Italy)를 이용 하여 $180^{\circ} \mathrm{C}$ 에서 20 분 동안 분해하여 분해액 중 비소의 함량을 ICP-MS (Agilent 7700, Santa Clara, CA, USA)로 분석하였다.
산 분해 후, vessel용기를 상온에서 충분히 냉각시킨 후 얻은 분해액을 $0.45 \mu \mathrm{m}$ 의 여과지로 여과한 다음 초순수 증류수로 25 $\mathrm{mL}$ 까지 정용하여 분석 시료로 사용하였다. 분석신뢰도를 확인 하기 위해 표준물질 IRMM-208 (rice)을 함께 분해한 후 동일 조건에서 분석을 실시하였고 회수율은 $80-120 \%$ 범위 내로 나 타났다.

\section{현미와 백미의 비소 화학종 분석}

현미와 백미 중 비소화학종의 분리 - 분석을 위해 분말화한 건 조 현미와 백미 시료 $0.1 \mathrm{~g}$ 을 $15 \mathrm{~mL}$ Teflon digestion tube에 넣어준 후 $1 \%$ 질산용액 $\left(\mathrm{HNO}_{3}\right) 10 \mathrm{~mL}$ 를 넣고 5분간 균질화 하여 준 다음 $80{ }^{\circ} \mathrm{C}$ water bath에서 30 분간 가열 추출 후 이를 상온에 냉각 후 원심분리기를 이용하여 $3000 \times \mathrm{g}$ 로 원심분리를 실시하였다. 원심분리 된 시료의 상등액을 $0.45 \mu \mathrm{m}$ membrane filter (Laboratory water purification system, Pall Life Science, Port Washington, NY, USA)로 여과하여 $15 \mathrm{~mL}$ conical tube 에 취하여 보관하였다. 비소의 화학종 분석에는 Hamilton PRPX100 anion exchange column을 사용한 HPLC-ICP-MS로 분석 하였는데, 분석 조건은 Williams 등의 방법[12]을 약간 수정한 $\mathrm{Kim}$ 등의 방법[10]을 사용하였다. 쌀 중 비소 화학종 분석은 표준시료(NIST 1568b)를 이용하여 $90-120 \%$ 의 회수율을 확인하 였다. 본 방법으로 정량이 가능한 비소화학종은 3가비소인 arsenite (As (III)), 5가비소인 arsenate (As (V)), Dimethylarsenic acid (DMA), Monomethylarsonic acid (MMA)이었다.

\section{백미의 무기비소 위해성평가}

본 실험에서 조사한 백미 중 무기비소 함량의 인체 위해성을 파악하기 위하여 이들 물질의 일일평균노출량(Average daily dose, $\mathrm{ADD})$ 을 산출하고(Eq. (1)), 발암위해도(Cancer risk probability, $\mathrm{CR})$ 와 비발암위해도(Hazard Quotient, $\mathrm{HQ}$ )를 평가하였다(Eq. (2)와 (3))[13-15].

$\mathrm{ADD}=\mathrm{C} \times \mathrm{IR} \times \mathrm{ED} \times \mathrm{EF} /(\mathrm{BW} \times \mathrm{AT} \times 365)$

$\mathrm{C}=$ Concentration of iAs in crop(백미 중 무기비소 함량, $\mathrm{mg} \mathrm{kg}^{-1}$ )

$\mathrm{IR}=$ Intake rate of crop(백미 섭취량, $\mathrm{kg} \mathrm{day}^{-1}, 0.168$ )

$\mathrm{ED}=$ Exposure duration(노출기간, year, 30)

$\mathrm{EF}=$ Exposure frequency(노출빈도, day $\mathrm{year}^{-1}, 365$ )

$\mathrm{BW}=$ Body weight(평균체중, $\mathrm{kg}, 72.3$ )

$\mathrm{AT}=$ Averaging time(평균수명, year, 78)

$\mathrm{CR}=\mathrm{ADD} \times \mathrm{SF}$

$\mathrm{SF}=$ Slope factor(발암잠재력, $1.5 \mathrm{mg} \mathrm{kg}^{-1} \mathrm{day}^{-1}$ )

$\mathrm{HQ}=\mathrm{ADD} / \mathrm{RfD}$

$\mathrm{RfD}=$ Reference dose(참고섭취량, $0.0003 \mathrm{mg} \mathrm{kg}^{-1} \mathrm{day}^{-1}$ )

\section{결과 및 고찰}

전국 쌀 주산단지에서 채취한 현미와 백미 시료의 총비소 함량 은 각각 $0.18 \mathrm{mg} \mathrm{kg}^{-1}\left(0.06-0.39 \mathrm{mg} \mathrm{kg}^{-1}\right)$ 과 $0.11 \mathrm{mg} \mathrm{kg}^{-1}$ (0.03$0.33 \mathrm{mg} \mathrm{kg}^{-1}$ )으로 나타났다(Table 1, 2). 이는 비소로 오염되지 
않은 논토양에서 조사된 Kunhikrishnan의 결과[8]인 현미 중 총 비소 함량 평균과 범위인 $0.15 \mathrm{mg} \mathrm{kg}^{-1} \quad\left(0.04-0.38 \mathrm{mg} \mathrm{kg}^{-1}\right)$ 과 유사하였으나, 폐광산 인근에서 채취한 현미와 백미 시료의 총 비소 함량인 각각 0.23 과 $0.13 \mathrm{mg} \mathrm{kg}^{-1}$ 보다는 낮은 경항을 보였 다[11]. 또한, 국내 마켓에서 구입한 50 개의 백미 시료의 총비 소 함량을 $0.105 \mathrm{mg} \mathrm{kg}^{-1}$ 으로 보고한 Choi 등의 결과[16]와 일 치하였다. 그러나 탑라이스 생산지역에서 조사된 현미와 백미 중 총비소 함량과 비교하면 2배이상의 차이를 보였다[17]. Fig. 1 은 현미 중 비소 전함량의 증가는 백미 중 비소 전함량과의 유의적인 증가를 보인다. 일반적으로 현미의 중(준)금속 함량이 백미의 중(준)금속 함량보다 높게 나타난 Park 등의 결과[17]와 유사하였으며 이는 종실 내보다 쌀겨에 비소가 주로 축적됨을 추정하였고, Choi 등[18]은 fs LA-ICP-MS (femtosecond Laser Ablation-Inductively Coupled Plasma-Mass Spectrometry)기기 를 사용한 현미 절편에서의 비소 분포영상을 통해 외피에 비소 가 높게 분포함을 확인하였다. 이는 도정에 의해 백미의 비소 함량을 줄일 수 있는 방법으로 제시될 수 있다. $\mathrm{CCCF}$ 에서는 현미의 분석 결과로서 백미의 함량을 추정하는 공정계수(processing factor)로 0.5 를 제안하였는데 Fig. 1의 기울기 0.5591과 유사함 을 확인하였다.

동일 시료 중 무기비소의 함량은 As (III)와 As (V)를 합한 값으로 현미 및 백미의 무기비소 평균함량과 범위가 각각 $0.11 \mathrm{mg} \mathrm{kg}^{-1}\left(0.04-0.23 \mathrm{mg} \mathrm{kg}^{-1}\right)$ 과 $0.07 \mathrm{mg} \mathrm{kg}^{-1} \quad\left(0.02-0.14 \mathrm{mg} \mathrm{kg}^{-1}\right)$ 으로 조사되어, 국내기준이며 $\mathrm{CCCF}$ 권장기준인 백미 중 무기 비소 $0.2 \mathrm{mg} \mathrm{kg}^{-1}$ 을 초과한 시료는 확인할 수 없었다(Table 1, 2). 또한 국내기준은 아직 미설정되어 있으나 $\mathrm{CCCF}$ 권장기준 인 현미 중 무기비소 $0.35 \mathrm{mg} \mathrm{kg}^{-1}$ 을 초과한 시료는 없었다. 현미 중 비소화학종의 비율은 As (III) $48.6 \%$, DMA $11.4 \%$, As (V) $16.9 \%$ 을 차지하고 있으며 $\mathrm{MMA}$ 는 검출한계 이하로 조사되었 다. 그 외 23.1\%는 타 비소화학종으로 추정된다(Table 1). 백미 중 비소화학종의 비율은 $\mathrm{As}$ (III) $57.5 \%$, DMA $18.4 \%$, As (V) $9.8 \%$ 을 차지하고 있으며 $\mathrm{MMA}$ 는 검출한계 이하로 조사되었다. 이러한 결과는 쌀 중의 비소화학종 중 가장 독성이 강한 As (III) 가 우세한 화학종으로 확인되었다. Choi 등의 보고[12]에서도 평균값으로 산정할 때 백미 중 비소화학종의 비율은 As (III) $67.6 \%$, DMA $18.1 \%$, As (V) 5.7\%을 차지하고 있으며 $\mathrm{MMA}$ 는 검출한계 이하로 조사되어 본 연구 결과와 유사하였다. Fig. 2 와 3은 백미 중 비소 총함량과 백미 중 무기비소 및 $\mathrm{DMA}$ 와 의 관계를 보여준다. 일반적인 선형모형식을 사용하여 백미 중 총비소 함량을 공변량으로 백미 중 무기비소 및 DMA 함량비 로 유의적인 상호작용을 확인할 수 있다[1]. 국내 생산 백미 중 총함량에 대한 무기비소의 회귀분석은 기울기가 0.3464 를 보여 Meharg 등[1]에서 조사한 인도(0.796), 방글라데시(0.719), 중국 (0.599), 이태리(0.506) 결과보다 낮은 수준을 보인 반면 미국 (0.275) 및 스페인(0.193)보다 높은 수준을 보였다. 또한, 총함량 에 대한 $\mathrm{DMA}$ 의 회귀분석은 기울기가 0.3792 를 보여 미국 (0.774)보다 낮은 수준을 다른 국가(0.137-0.199)보다는 높은 수 준을 보였다. 백미 중 무기비소와 DMA함량비로서 지역적인 차 이를 확인할 수 있으나 Meharg 등의 보고[1]는 극히 제한된 시 료수로서 조사된 결과로서 이러한 관계를 확립하기 위해서는 더 많은 조사 결과가 필요한 실정이다.

본 조사에서 수행한 백미 중 무기비소 모니터링 한 결과에

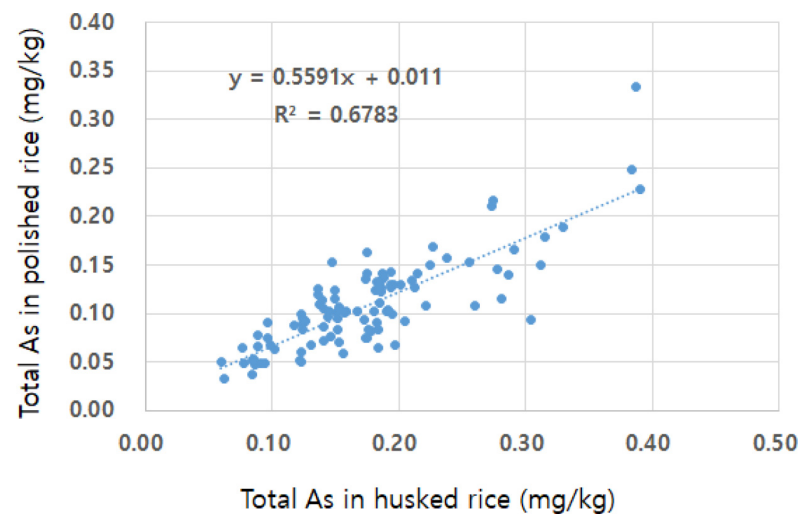

Fig. 1 Correlation between total As in husked rice and polished rice grown at the non-contaminated paddy fields in Korea

Table 1 Arsenic speciation concentrations in husked rice grown at the non-contaminated paddy soils in Korea $(n=100)$

\begin{tabular}{cccccc}
\hline \hline & Total As & As (III) & DMA & MMA & As (V) \\
\cline { 2 - 6 } & \multicolumn{5}{c}{$\mathrm{mg} \mathrm{kg}^{-1}$} \\
\hline Average \pm SD & $0.18 \pm 0.07$ & $0.08 \pm 0.03$ & $0.02 \pm 0.02$ & $0.00 \pm 0.00$ & $0.03 \pm 0.02$ \\
Median & 0.15 & 0.06 & 0.01 & 0.00 & 0.02 \\
Min & 0.06 & 0.02 & 0.00 & 0.00 & 0.00 \\
Max & 0.39 & 0.16 & 0.13 & 0.00 & 0.08 \\
95 Percentile & 0.31 & 0.13 & 0.06 & 0.00 & 0.06 \\
\hline
\end{tabular}

Table 2 Arsenic speciation concentrations in polished rice grown at the non-contaminated paddy soils in Korea $(n=100)$

\begin{tabular}{cccccc}
\hline \hline & Total As & As (III) & DMA & MMA & As (V) \\
\cline { 2 - 6 } & \multicolumn{5}{c}{ mg kg } \\
\hline Average \pm SD & $0.11 \pm 0.05$ & $0.06 \pm 0.02$ & $0.02 \pm 0.03$ & $0.00 \pm 0.00$ & $0.01 \pm 0.01$ \\
Median & 0.13 & 0.06 & 0.03 & 0.00 & 0.02 \\
Min & 0.03 & 0.01 & 0.00 & 0.00 & 0.00 \\
Max & 0.33 & 0.14 & 0.24 & 0.00 & 0.07 \\
95 Percentile & 0.19 & 0.11 & 0.06 & 0.00 & 0.02 \\
\hline
\end{tabular}

대한 비발암 $(\mathrm{HQ})$ 및 발암 $(\mathrm{CR})$ 위해도 결과는 Table 3 과 같다. 백미에서 비발암 위해도 산출 결과는 평균과 범위가 0.208 (0.053-0.421)로서 허용 수준인 1.0 을 고려할 때 비발암위해 가 능성은 매우 낮았다. 또한, 발암 위해도도 평균과 범위가 $9.37 \times$ $10^{-5}\left(2.38 \times 10^{-5}-1.90 \times 10^{-4}\right)$ 로 미국환경보호청(United States Environmental Protection Agency, US EPA)의 허용 수준인 $10^{-6}-10^{-4}$ 을 고려할 때 장기간의 쌀 섭취를 통한 암발생 확률은 낮게 나타나 위해성이 낮은 것으로 판단된다. 이러한 결과는 우 리나라 22개의 폐광산 인근에서 채취한 백미 시료의 무기비소 함량을 바탕으로 산출된 발암위해 평균확률이 10 만명 당 5.7 명 으로 조사와 유사한 경향을 보였다[11]. 그러나, 또 다른 폐금 속 광산지역에서의 쌀 섭취의 노출경로를 통한 비소에 의한 암 발생 확률이 천명 당 3.1-6.8명으로 높게 나타남을 보고하였다 [19]. 이러한 결과는 쌀 중의 총비소 함량을 근거로 위해성을 평가하여 무기비소 함량을 근거한 본 결과와는 차이가 있으나 백미의 총비소 함량이 $0.35-0.76 \mathrm{mg} \mathrm{kg}^{-1}$ 으로 조사되어 백미 중 총비소 함량이 $0.11 \mathrm{mg} \mathrm{kg}^{-1}$ 인 본 조사에 비해 위해성이 큰 것 


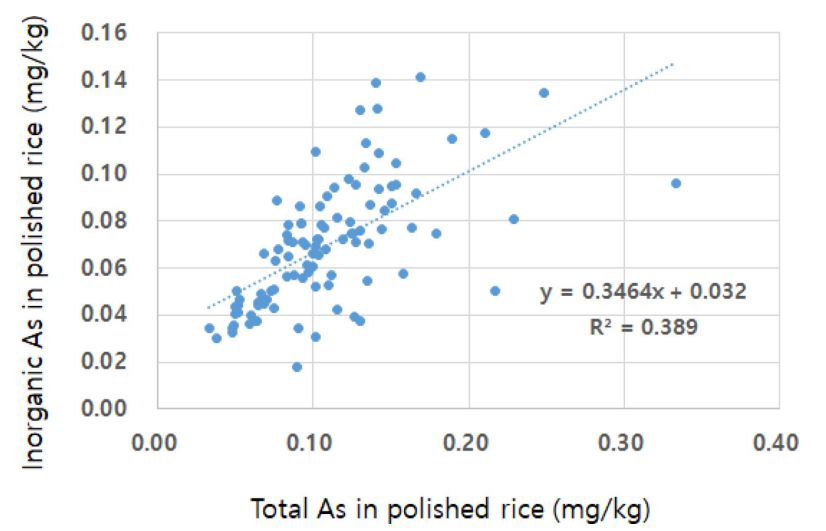

Fig. 2 Regression of inorganic As against total As in polished rice grown at the non-contaminated paddy soils in Korea

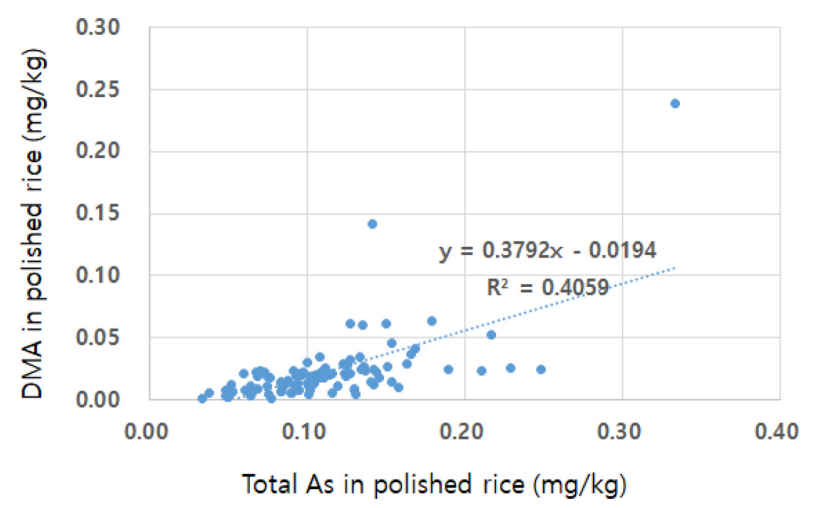

Fig. 3 Regression of DMA against total As in polished rice grown at the non-contaminated paddy soils in Korea

\section{으로 추정된다.}

비소는 자연적으로 암석의 풍화작용과 충적물의 퇴적물로서 또한, 화석연료의 연소, 제련과 폐광산 등 산업활동, 비소함유 제초제 등 인위적인 요인을 통해 토양과 지하수에 축적되고 생 물권 먹이 연쇄계를 통해 인체에 유입되어 다양한 질병을 유발 하는 환경오염물질이다[3,20]. 최근의 연구는 쌀의 높은 비소농 도가 관개수와 토양의 비소함량에 의해 결정된다는 것과 또 다 른 연구는 토양-근권-식물체 체계에서 비소 용해도, 생물학적 유 효도 및 흡수를 통해 쌀의 비소농도가 결정된다고 보고하였다 [20]. 또한, 쌀 중 비소함량에 대한 국가간 큰 차이를 보였고, 최대 $2.05 \mathrm{mg} \mathrm{kg}^{-1}$ 의 수치가 방글라데시 서부지역에서 조사되었 음을 보고하였다[20]. Dittmar 등[21]은 방글라데시에서는 벼농 사에 비소가 다량 함유된 지하수를 건조기에 관개수로 사용하 고 있고 이는 쌀의 비소오염과 더불어 장기적인 비소의 토양 축적의 요인으로 보고하였다. 우리나라의 경우 폐광산 등 비소 오염이 취약한 지역에서의 관개수의 비소 모니터링에 대한 자 료가 극히 제한적이다. 그럼에도 불구하고, Lee 등[22]은 중금 속 오염에 취약한 22 개 지역의 논토양에서 비소함량의 평균과 범위가 $33.58(0.95-274.76) \mathrm{mg} \mathrm{kg}^{-1}$ 으로 조사되어 토양환경보전 법에서 정하는 토양오염우려기준인 $25 \mathrm{mg} \mathrm{kg}^{-1}$ 을 크게 초과하고 이는 광산폐기물의 농경지 유입과 더불어 폐광산 인근 지하수 의 비소오염이 예상되는 바 이에 대한 관리 및 추가조사가 수
Table 3 Cancer risk probability and hazard quotient of As in polished rice

\begin{tabular}{ccc}
\hline \hline & Cancer risk probability & Hazard quotient \\
\hline Average & $9.37 \mathrm{E}-05$ & 0.208 \\
Min & $2.38 \mathrm{E}-05$ & 0.053 \\
Max & $1.90 \mathrm{E}-04$ & 0.421 \\
\hline
\end{tabular}

행되어야 할 것이다.

결론적으로, 본 논문은 최근 이슈화된 백미의 무기비소 기준 설정 및 위해 관리를 위한 과학적 근거 자료로서 국내자료를 수집할 필요가 있어 추진되었다. 전국적인 쌀 주산단지 100지 점에서 재배한 현미와 백미 중 무기비소의 평균 함량이 각각 0.11 과 $0.07 \mathrm{mg} \mathrm{kg}^{-1}$ 으로 조사되어 $\mathrm{CCCF}$ 의 허용기준인 0.35 과 $0.2 \mathrm{mg} \mathrm{kg}^{-1}$ 의 기준치를 초과하지 않아 안전한 수준으로 확인되 었다. 그러나 조사지점에 따라 현미의 무기비소 함량은 최대 $0.23 \mathrm{mg} \mathrm{kg}^{-1}$, 백미의 경우 $0.14 \mathrm{mg} \mathrm{kg}^{-1}$ 으로 허용기준의 약 $70 \%$ 함량을 보여 관개용수 및 토양의 비소함량이 취약한 지역 에서는 기준을 초과하는 쌀의 생산이 우려되고 이에 대한 관리 가 요구된다.

\section{초 록}

논토양과 쌀의 비소 오염은 식품의 안전성과 관련하여 관심이 증가하고 있다. 본 연구는 우리나라 비오염 논토양에서 생산된 현미와 백미 중 비소 총함량 및 무기비소 함량을 조사하였다. 쌀 중 비소화학종은 $1 \%$ 질산 $\left(\mathrm{HNO}_{3}\right)$ 을 사용하여 추출하였고 HPLC-ICP-MS로 분석하였다. 현미 및 백미 중 총비소 함량은 각각 $0.18,0.11 \mathrm{mg} \mathrm{kg}^{-1}$ 이었고, 무기비소의 함량은 각각 0.11 , $0.07 \mathrm{mg} \mathrm{kg}^{-1}$ 이었다. 이들 함량은 코덱스 식품규격위원회 권장 기준인 현미 $0.35 \mathrm{mg} \mathrm{kg}^{-1}$ 과 백미 $0.2 \mathrm{mg} \mathrm{kg}^{-1}$ 을 초과하지 않았 고 우리나라 백미 기준 이하로 안전한 수준이었다. 현미 및 백 미 중 총비소 함량에 대한 무기비소의 평균 함량비은 각각 0.65 과 0.67이고 범위는 0.08-1.0 수준이었다. 본 조사에서 수행한 백미 중 무기비소 모니터링 한 결과에 대한 발암 위해도는 평 균과 범위가 $9.37 \times 10^{-5}\left(2.38 \times 10^{-5}-1.90 \times 10^{-4}\right)$ 로 허용 수준인 $10^{-6}-10^{-4}$ 을 고려할 때 장기간의 쌀 섭취를 통한 암발생 확률은 낮게 나타나 위해성이 낮은 것으로 판단된다.

Keywords 모니터링 - 무기비소 · 백미 · 비소 · 현미

Acknowledgment This study was financially supported by "Research Program for Agricultural Science \& Technology Development (Project No. PJ013392)" National Institute of Agricultural Science, Rural Development Administration, Korea.

\section{References}

1. Meharg AA, Williams PN, Adomako EE, Lawgali YY, Deacon C, Villada A, Cambell RCJ, Sun G, Zhu YG, Feldmann J, Raab A, Zhao FJ, Islam R, Hossain S, Yanai J (2009) Geographical variation in total and inorganic arsenic content of polished (white) rice. Environ Sci Technol 43: 1612-1617 
2. Bhattacharya S, Gupta K, Debnath S, Ghosh UC, Chattopadhyay D, Mukhopadhyay A (2012) Arsenic bioaccumulation in rice and edible plants and subsequent transmission through food chain in Bengal basin: a review of the perspectives for environmental health. Toxicol Environ Chem 94(3) : 429-441

3. Yang SH, Park JS, Cho MJ, Choi H (2016) Risk analysis of inorganic in foods. J Food Hyg Saf 31(4) : 227-249

4. Codex Alimentarius Commission (CAC) (2014). Joint FAO/WHO Food Standards Programme. 37th Session Report, Geneva

5. Codex Alimentarius Commission (CAC) (2016). Joint FAO/WHO Food Standards Programme. 39th Session Report, Berlin

6. Kim WI, Yang JE, Jung GB, Park BJ, Park SW, Kim JK, Kwon OK, Ryu GH (2007) Bioavailability and safety of heavy metals in paddy soilrice continuum in Korea. FFTC Technical Bulletin 597

7. Park SW, Yoon MY, Kim JK, Park BJ, Kim WI, Shin JD, Kwon OK, Chung DH (2008) Rice safety and heavy metal contents in the soil on "Top rice" cultivation area. J Food Hyg Saf 23(3): 239-247

8. Kunhikrishnan A, Go WR, Park JH, Kim KR, Kim HS, Kim KH, Kim WI, Cho NJ (2012) Heavy metal(loid) levels in paddy soils and brown rice in Korea. Korean J Soil Sci Fert 48(5): 515-521

9. Paik MK, Kim MJ, Kim WI, Yoo JH, Park BJ, Im GJ, Park JE, Hong MK (2010) Determination of arsenic species in polished rice using a methanol-water digestion method. J Korean Soc Appl Biol Chem 53(5): 634-638

10. Kim JY, Kim WI, Kunhikrishnan A, Kang DW, Kim DH, Lee YJ, Kim YJ, Kim CT (2013) Determination of arsenic species in rice grains using HPLC-ICP-MS. Food Sci Biotechnol 22(6): 1509-1513

11. Kim HS, Kang DW, Kim DI, Lee S, Park SW, Yoo JH, Kim WI (2016) Inorganic As concentration in rice grown around the abandoned mining areas and its health risk assessment. Korean J Soil Sci Fert 49(5): 584 588

12. Williams PN, Islam MR, Adomako EE, Raab A, Hossain S, Zhu YG, Feldmann J, Meharg AA (2006) Increase in rice grain arsenic for regions of Bangladesh irrigating paddies with elevated arsenic in groundwaters.
Environ Sci Technol 40: 4903-4908

13. Kim WI, Kim JK, Yoo JH, Paik MK, Park SW, Kwon OK, Hong MK, Yang JE, Kim JG (2009) Risk assessment of $\mathrm{As}, \mathrm{Cd}, \mathrm{Cu}$ and $\mathrm{Pb}$ in different rice varieties grown on the contaminated soil. Korean J Soil Sci Fert 42(1): 53-57

14. Mondal D, Polya D (2008) Rice in a major exposure route for arsenic in Chakdaha block, Nadia district, West Bengal, India: A probabilistic risk assessment. Appl Geochem 23: 2987-2998

15. US EPA (2001) Risk assessment guidance for superfund: volume -part A, process for conducting probabilistic risk assessment. Washington, DC

16. Choi JY, Khan N, Nho EY, Choi H, Park KS, Cho MJ, Youn HJ, Kim KS (2016) Speciation of arsenic in rice by high-performance liquid chromatography-inductively coupled plasma mass spectrometry. Analytical Letters 49(12): 1926-1937

17. Park SW, Yang JS, Ryu SW, Kim DY, Shin JD, Kim WI, Choi JH, Kim SL, Saint AF (2009) Uptake and translocation of heavy metals to rice plant on paddy soils in "Top-rice" cultivation areas. Korean J Environ Agri 28(2): 131-138

18. Choi SH, Kim JS, Lee JY, Jeon JS, Kim JW, Russo RE, Gonzalez J, Yoo JH, Kim KS, Yang JS, Park KS (2014) Analysis of arsenic in rice grain using ICP-MS and fs LA-ICP-MS. J Anal At Spectrom 29: 1233-1237

19. Lee JS, Kwon HH, Shim YS, Kim TH (2007) Risk assessment of heavy metals in the vicinity of the abandoned metal mine areas. J of KoSSGE 12(1): 97-102

20. Sahoo PK, Kim K (2013) A review of the arsenic concentration in paddy rice from the perspective of geoscience. Geosciences J 17(1): 107-122

21. Dittmar J, Voegelin A, Maurer F, Roberts LC, Hug SJ, Saha GC, Ali MA, Badruzzaman ABM, Kretzschmar R (2010) Arsenic in soil and irrigation water affects arsenic uptake by rice: Complementary insights from field and pot studies. Environ Sci Technol 44: 8842-8848

22. Lee S, Kang DW, Yoo JH, Park SW, Oh KS, Lee JH, Cho IK, Moon BC, Kim WI (2017) Determination of bioconcentration factor of heavy metal(loid)s in rice grown on soils vulnerable to heavy metal(loid)s contamination. Korean J Soil Sci Fert 50(2): 106-114 